Ángulo Recto. Revista de estudios sobre la ciudad como espacio plural ISSN: $1989-4015$

\title{
Iconografía urbana
}

Federico Romero Galán

Monumentos, esculturas, edificios, rincones..., a través de los cuales se identifica una ciudad. Las fotografías han sido tomadas en Casablanca, Edimburgo, París, Londres, Berlín, Tánger, Dresde, Nueva York, Praga, Cracovia, Palermo, Dublín, Carcassonne, Florencia, Pisa, La Valetta, Toulouse, Jerusalén, Sevilla, Madrid, Roma, Barcelona, Estambul, Marrakech, Lisboa y Pekín. Sirva de ejemplo el caso de Edimburgo, ciudad identificada a través del Corazón de Midlothian, un corazón de adoquines, cerca de la Catedral, que ocupa el lugar donde estuvo la cárcel y sobre el que es costumbre escupir al pasar. El corazón de Midlothian da título a una novela del escritor escocés Walter Scott en la que se describen acontecimientos ocurridos en esta región escocesa.

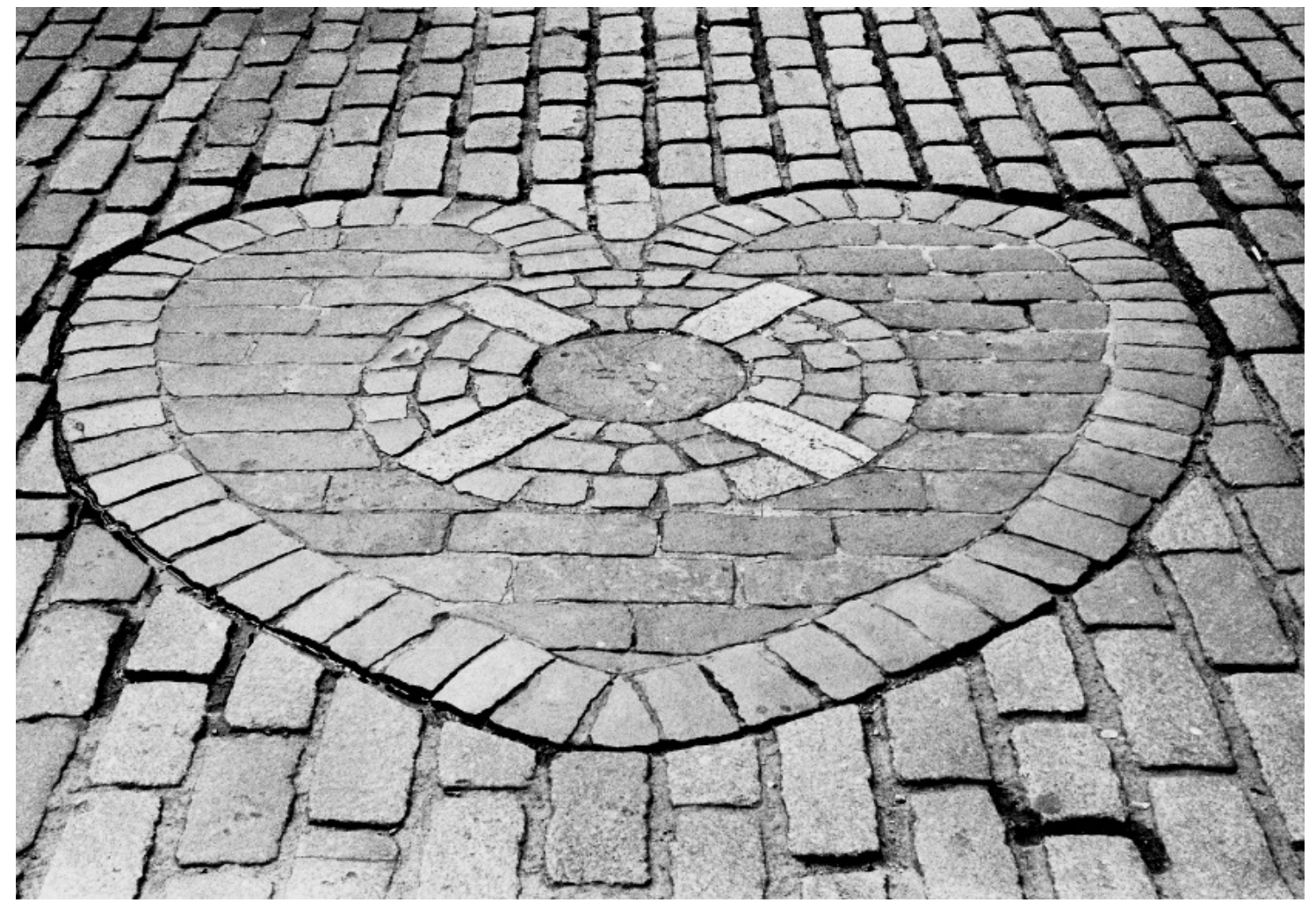



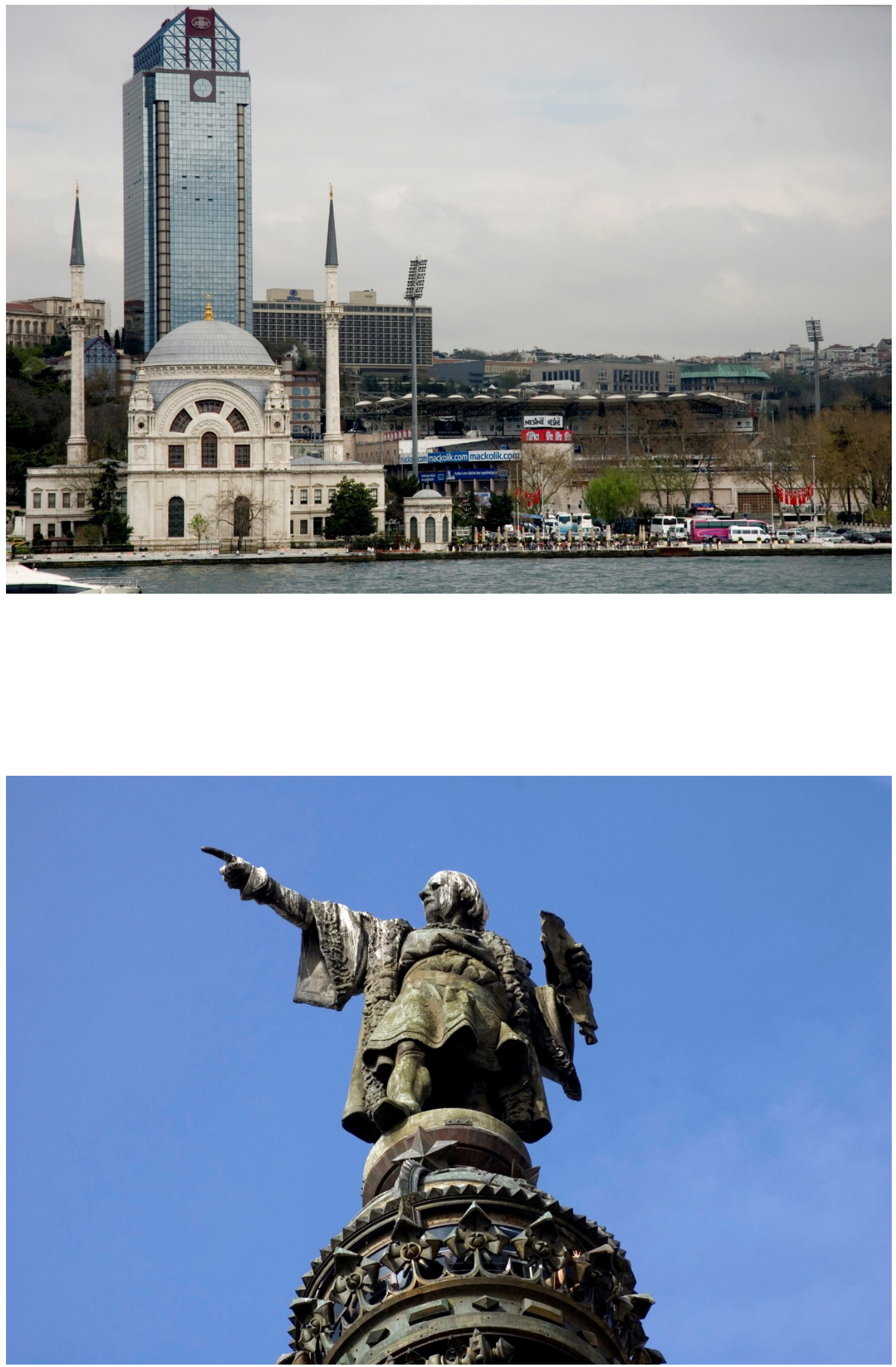

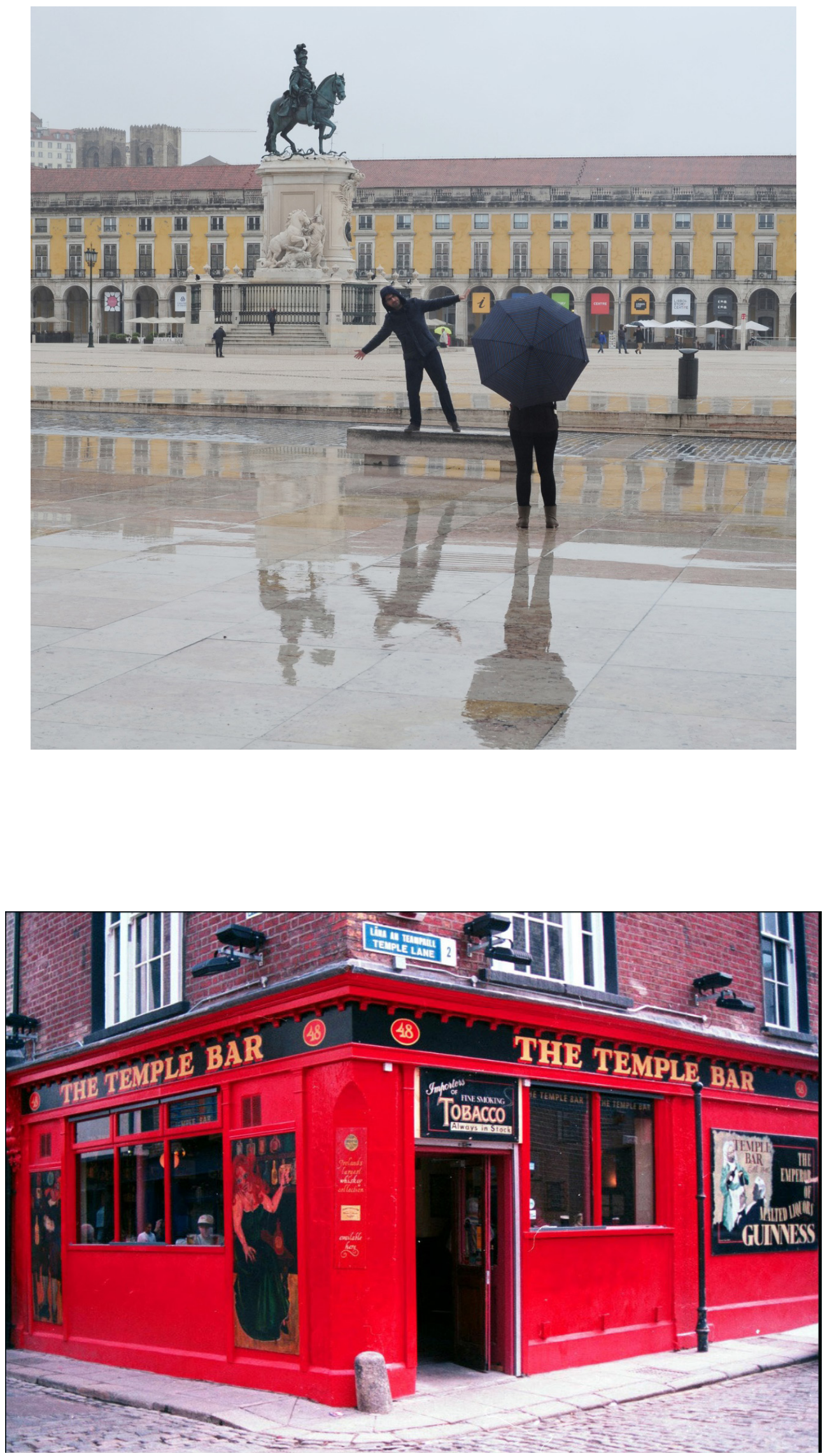

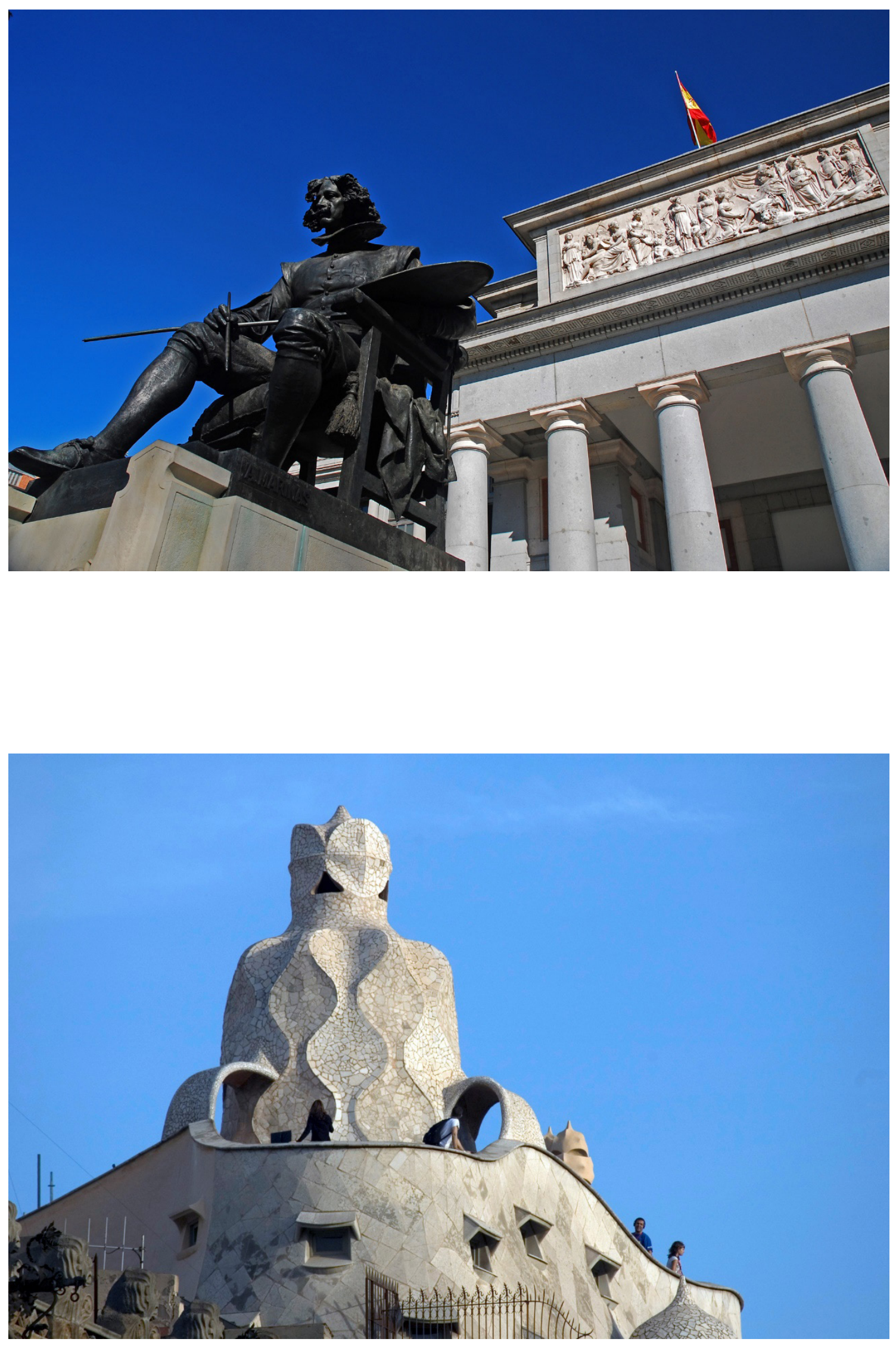

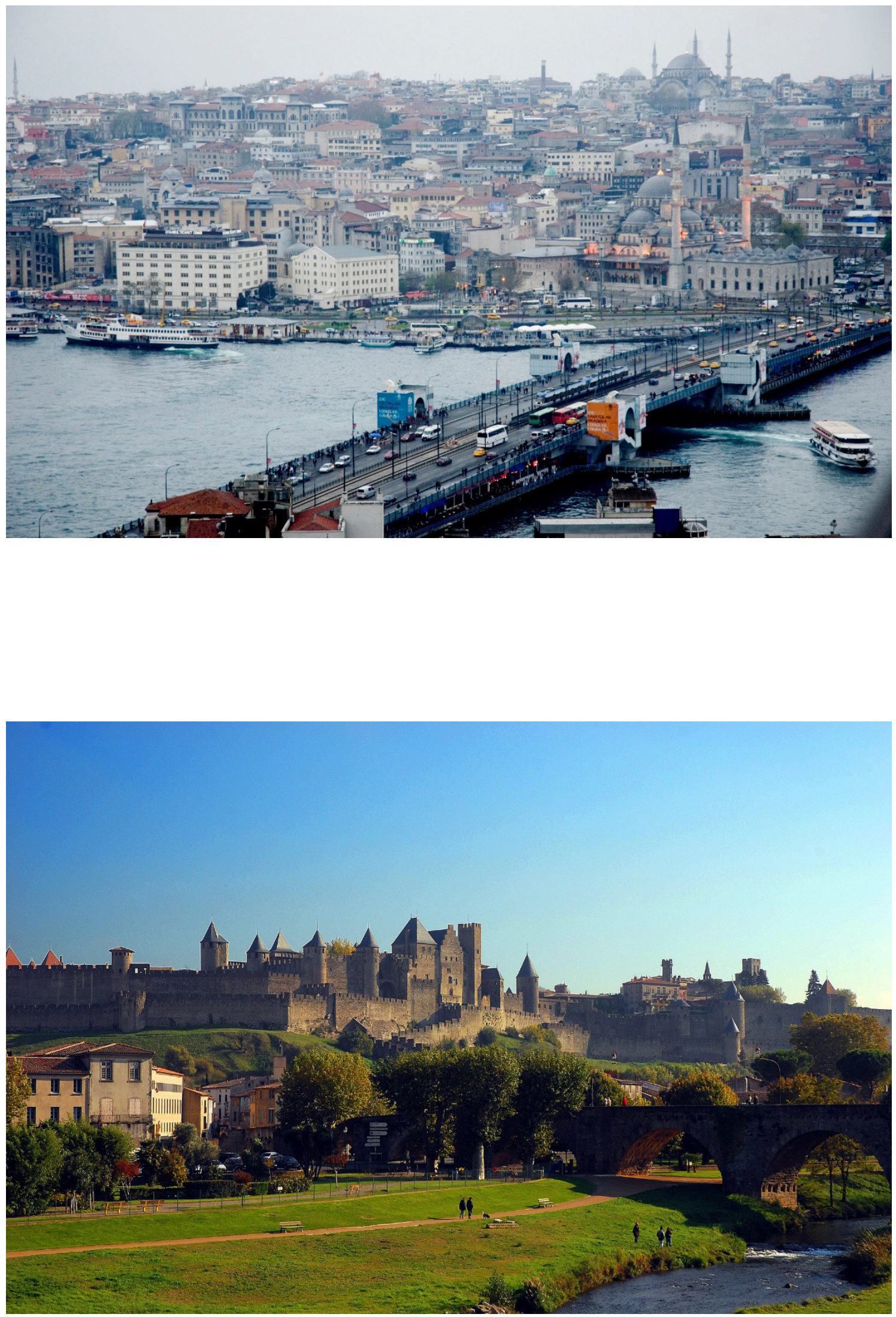

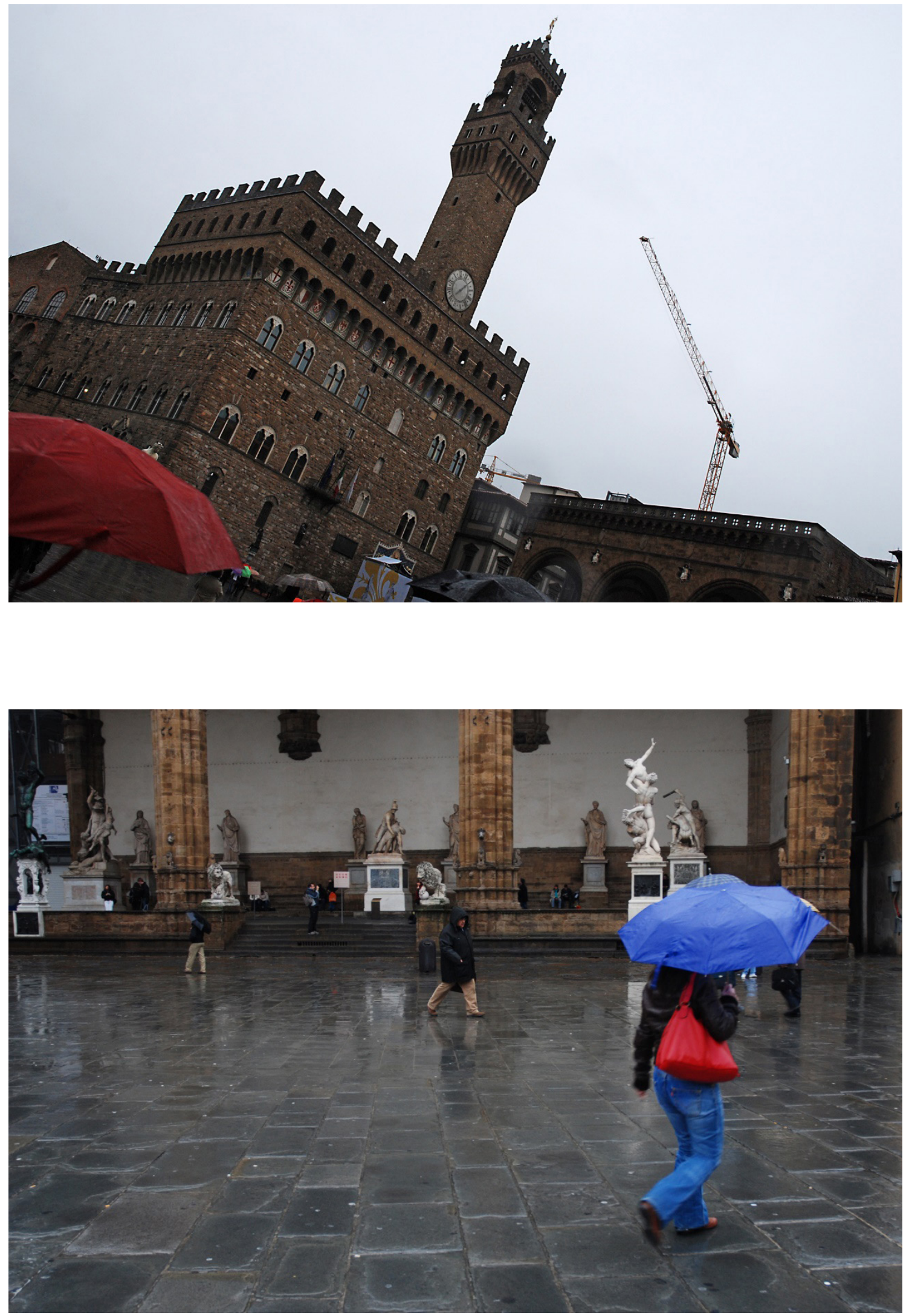


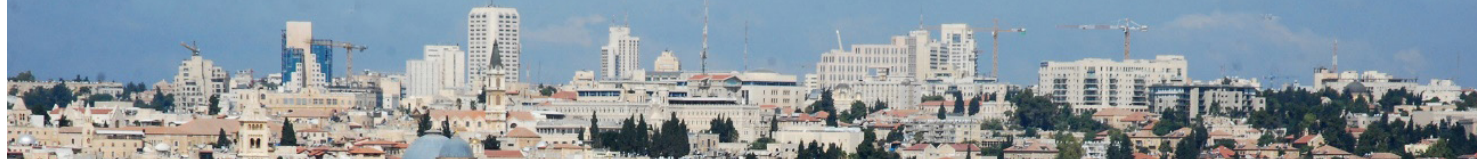

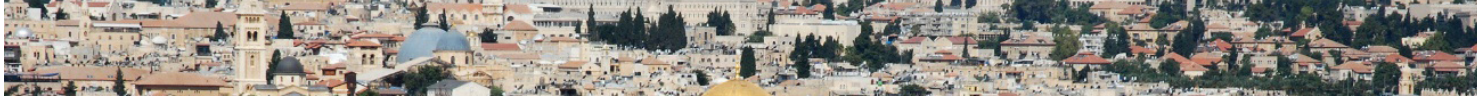

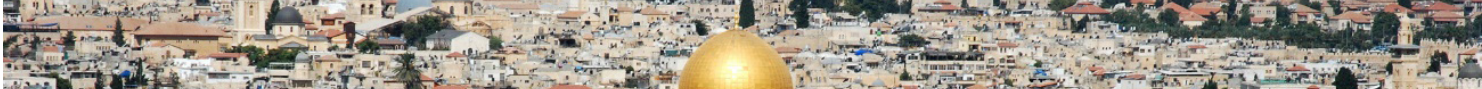
3.

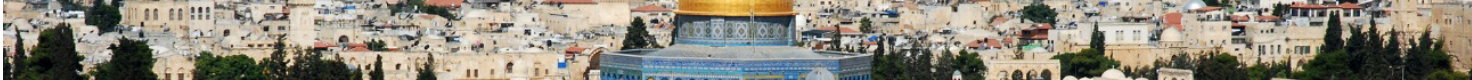

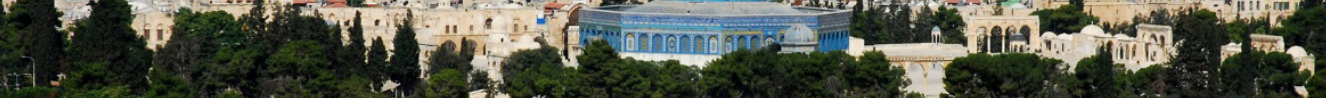

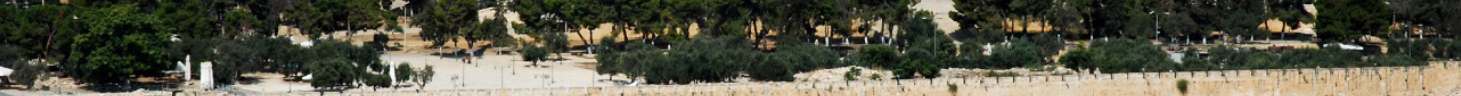

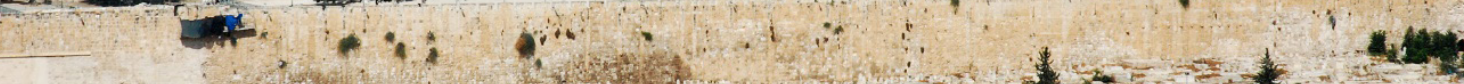

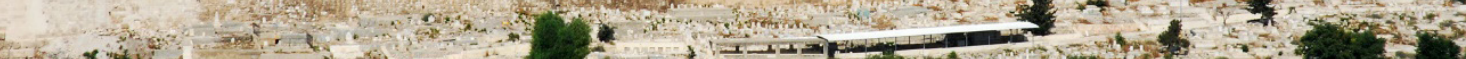

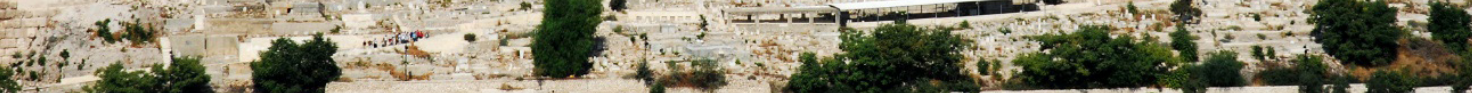

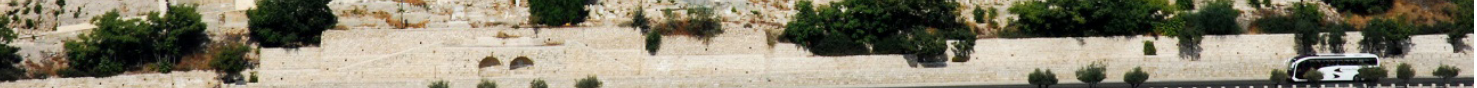

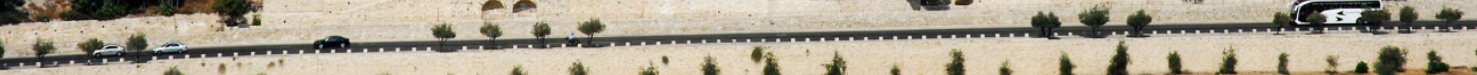

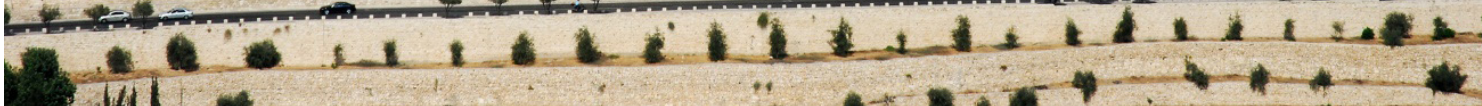

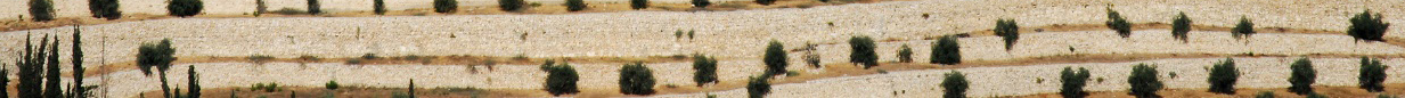

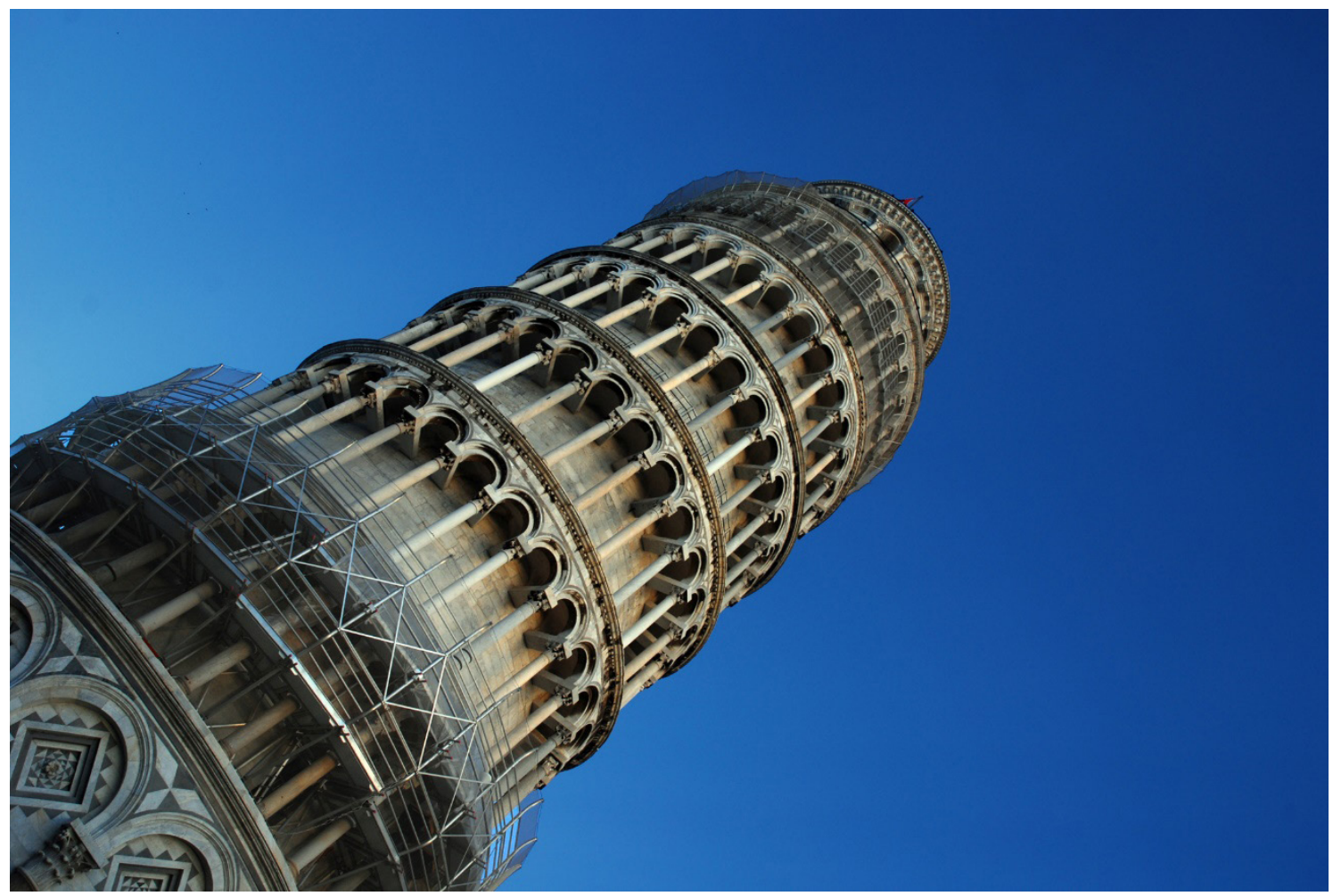



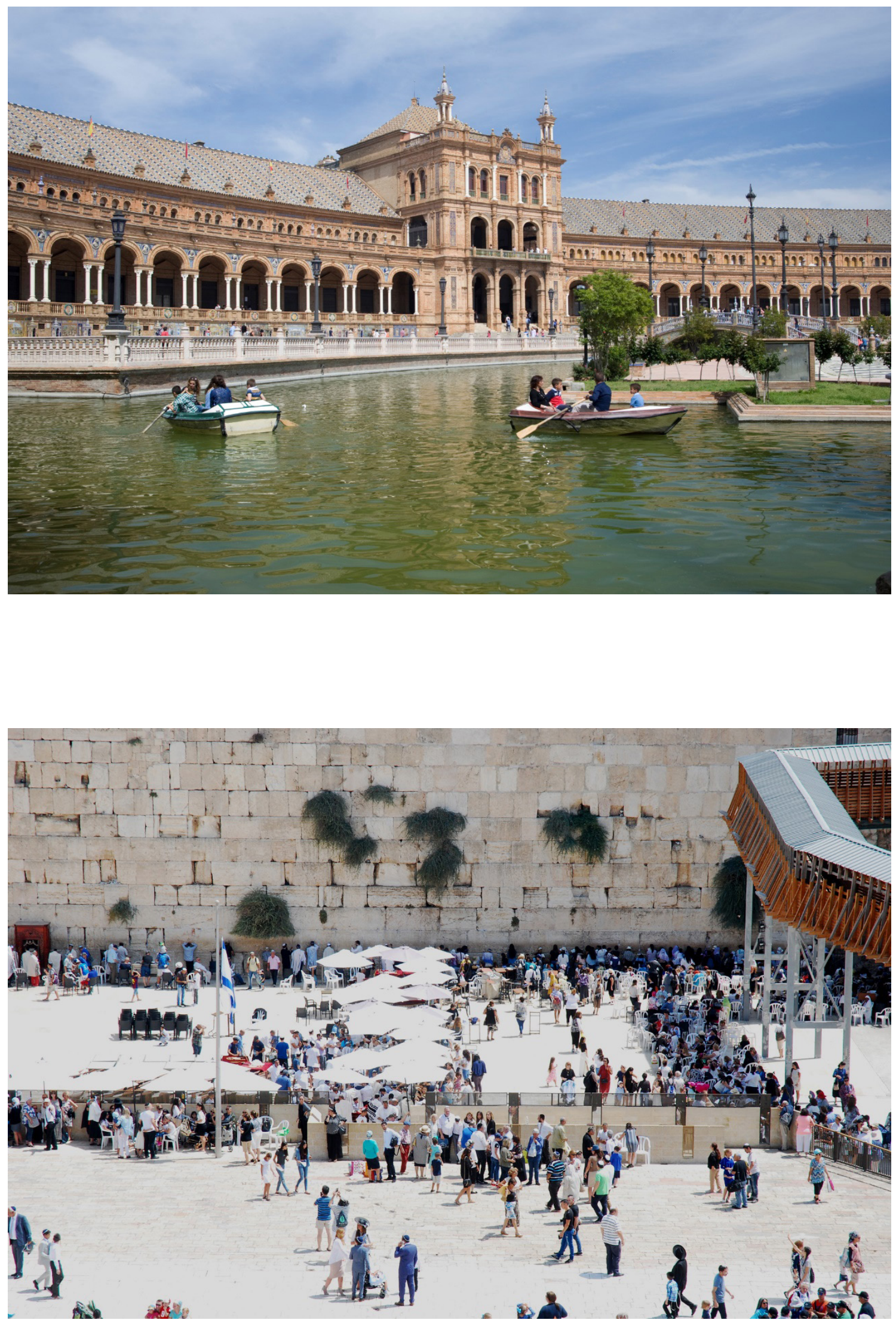

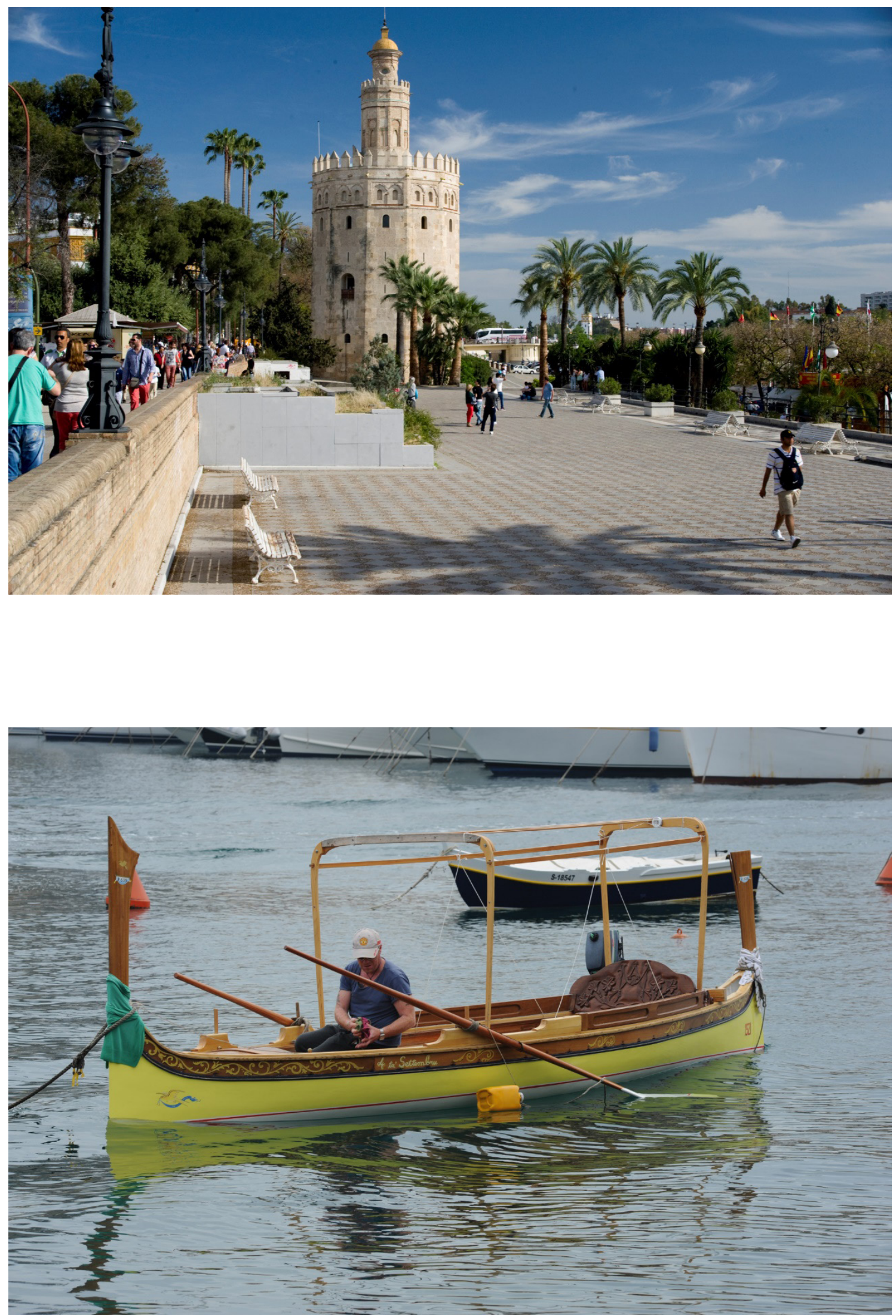

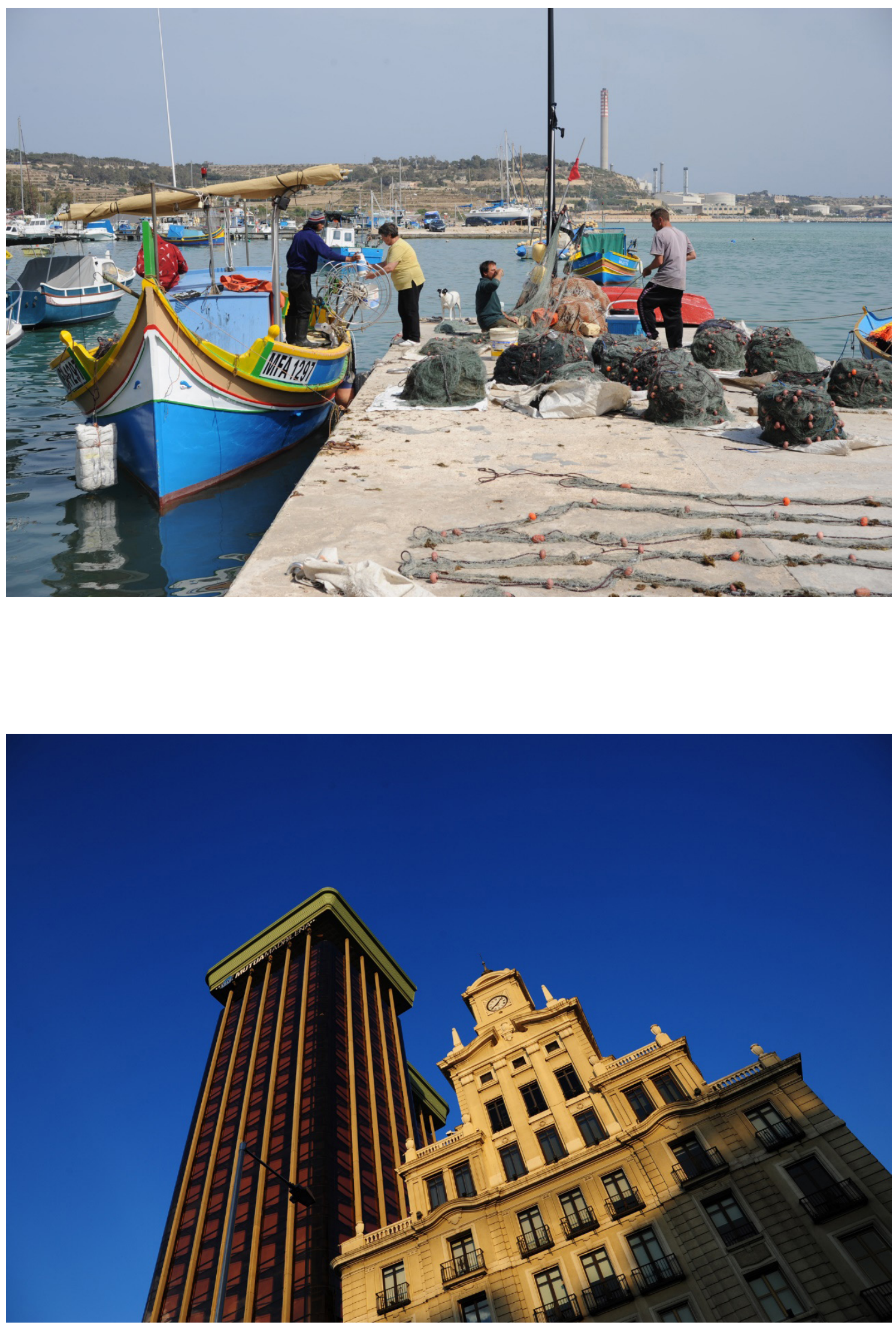


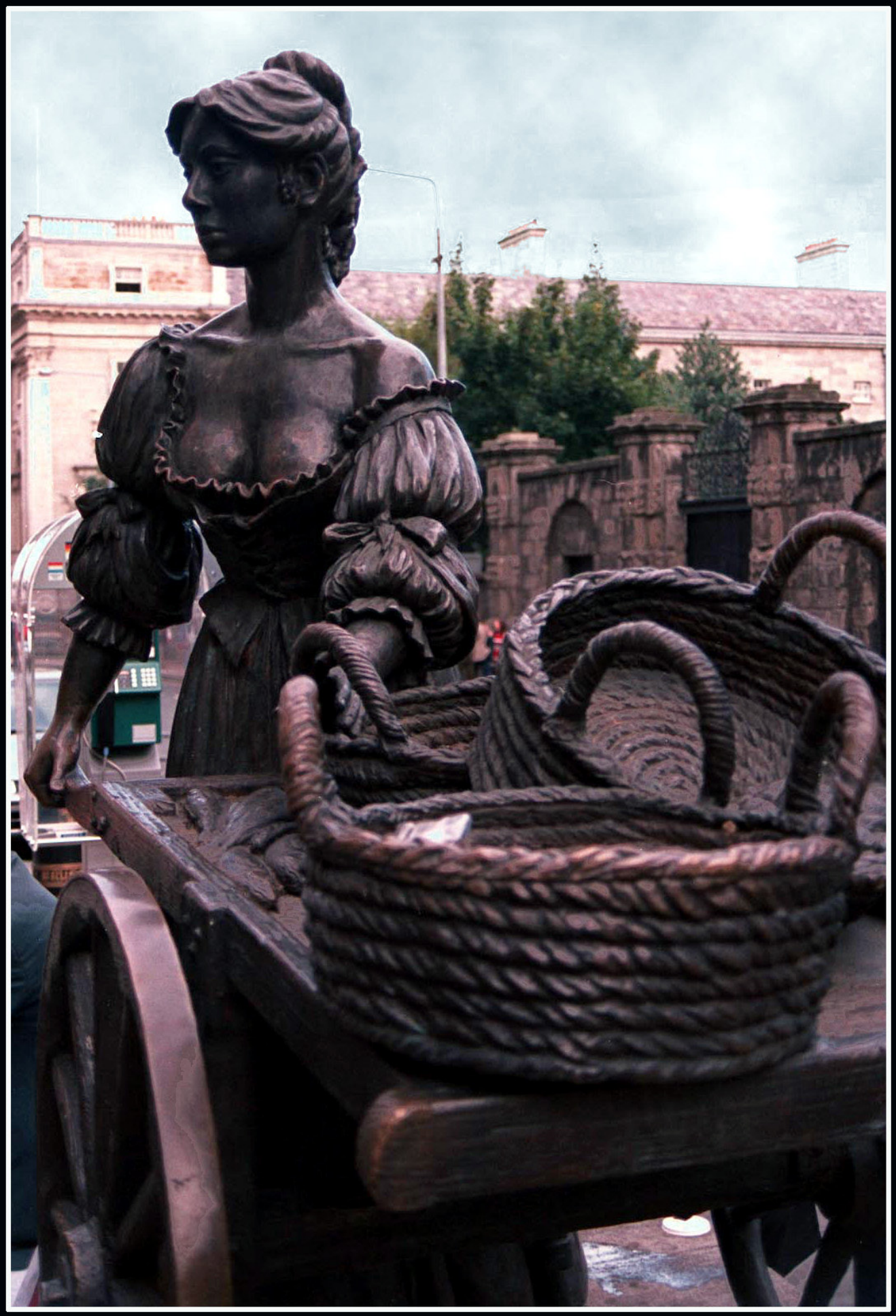



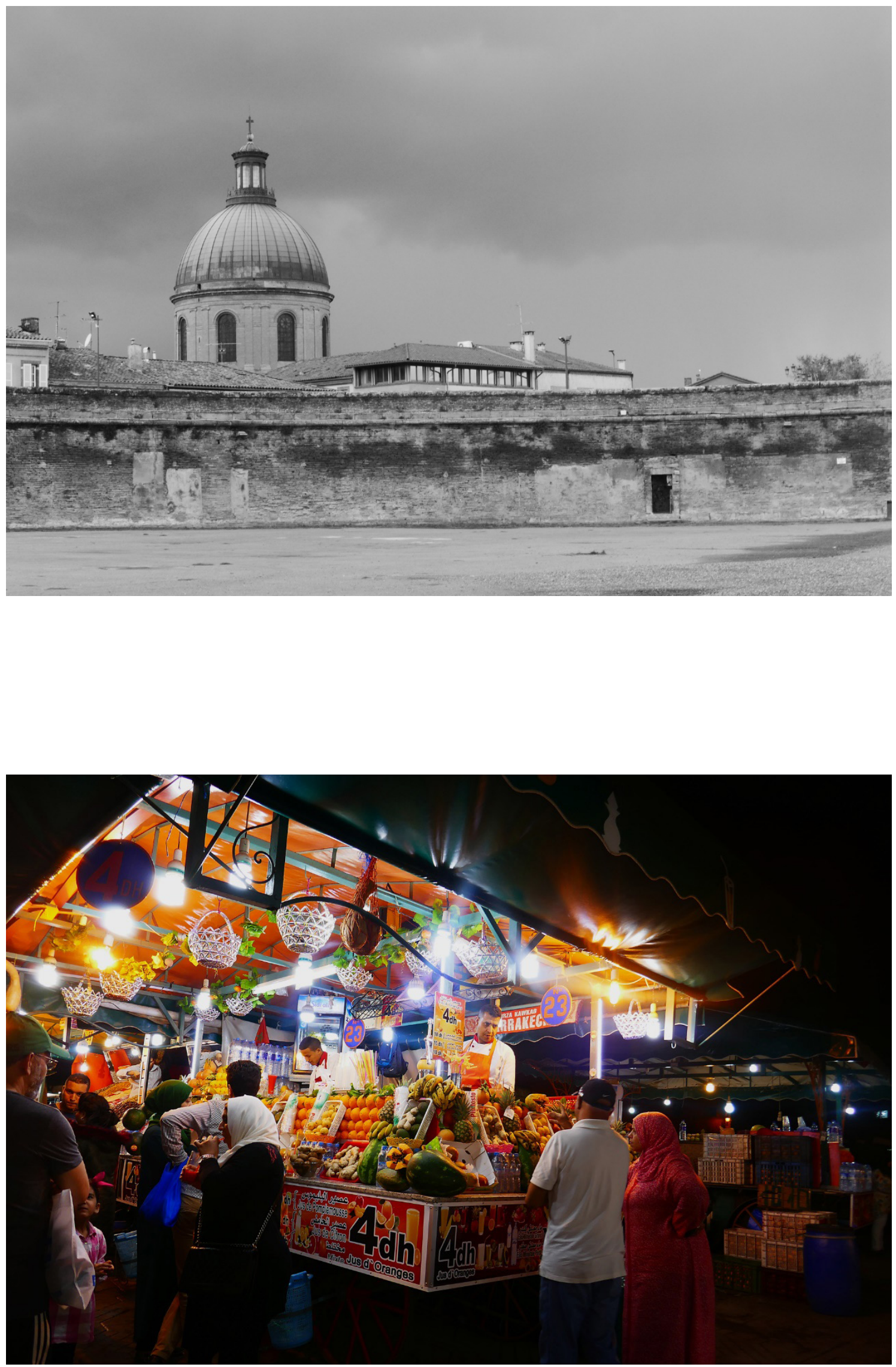

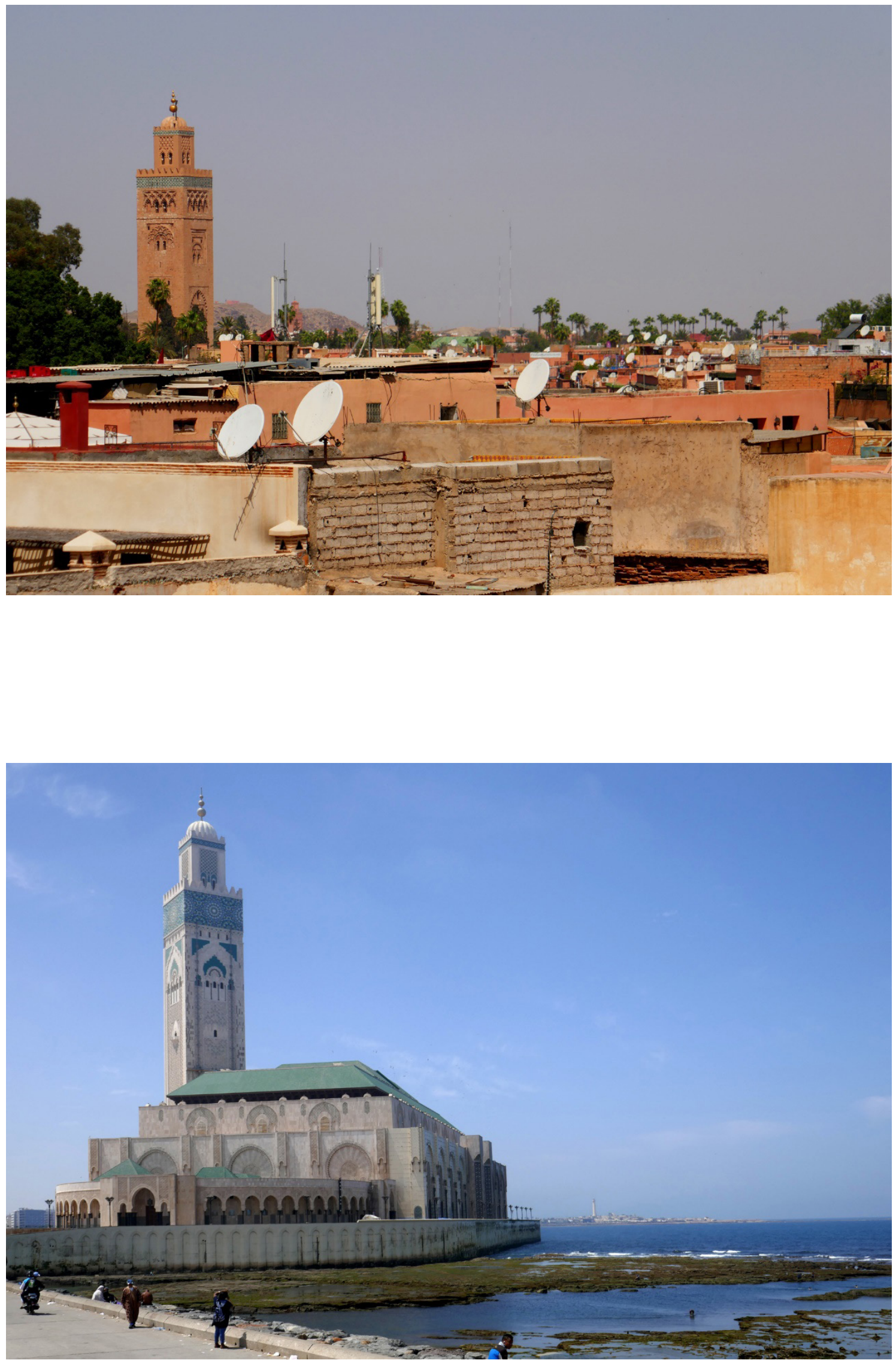

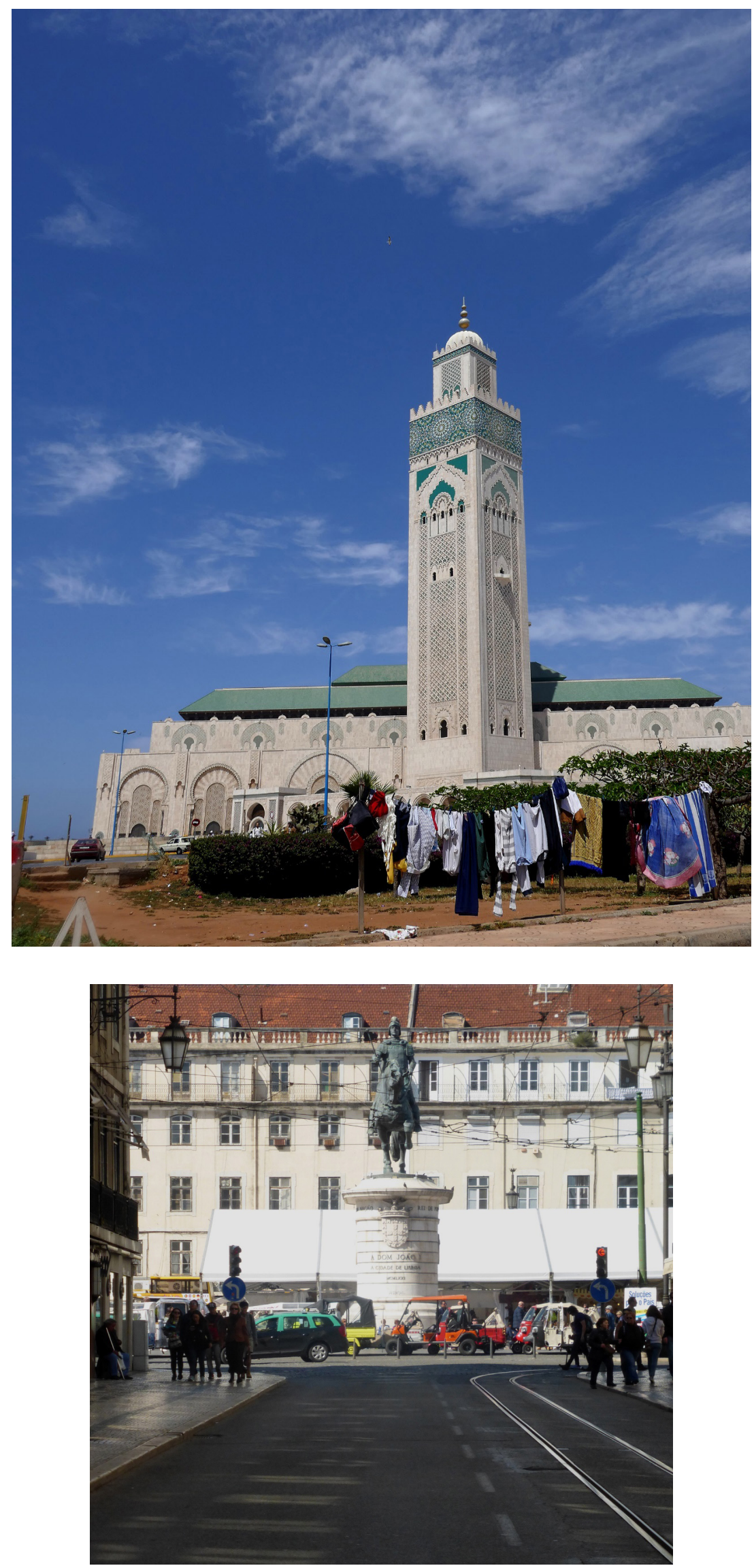

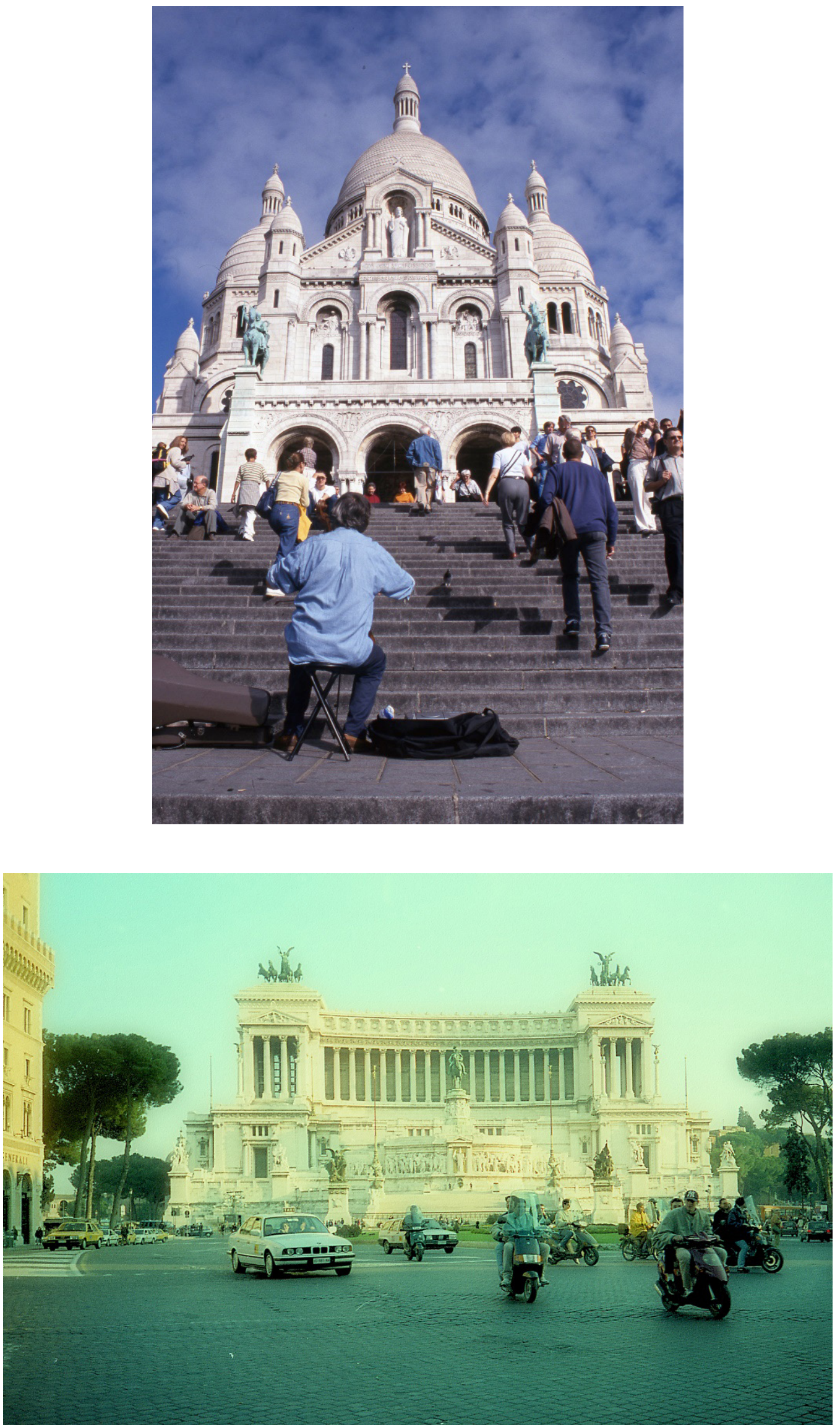

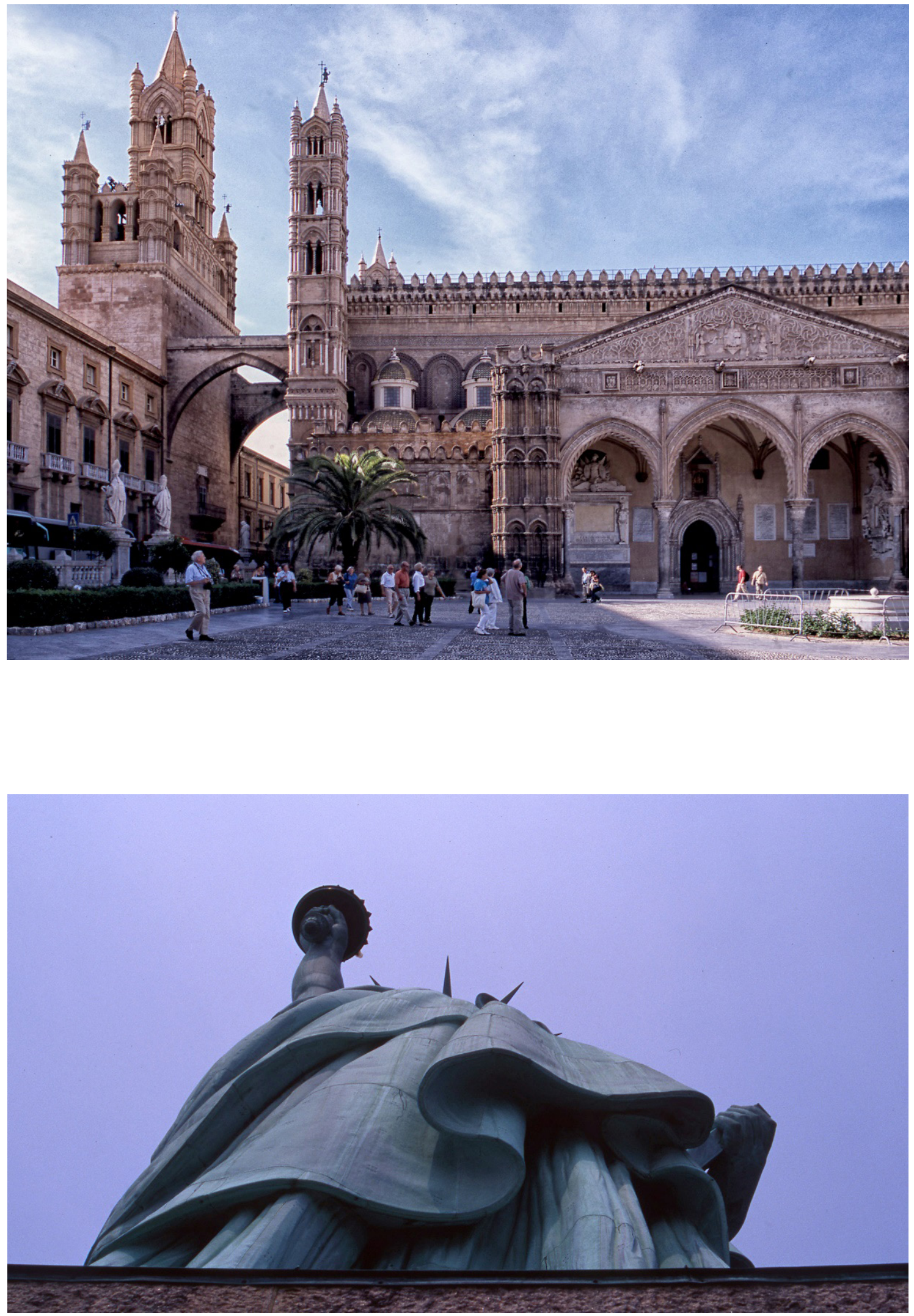

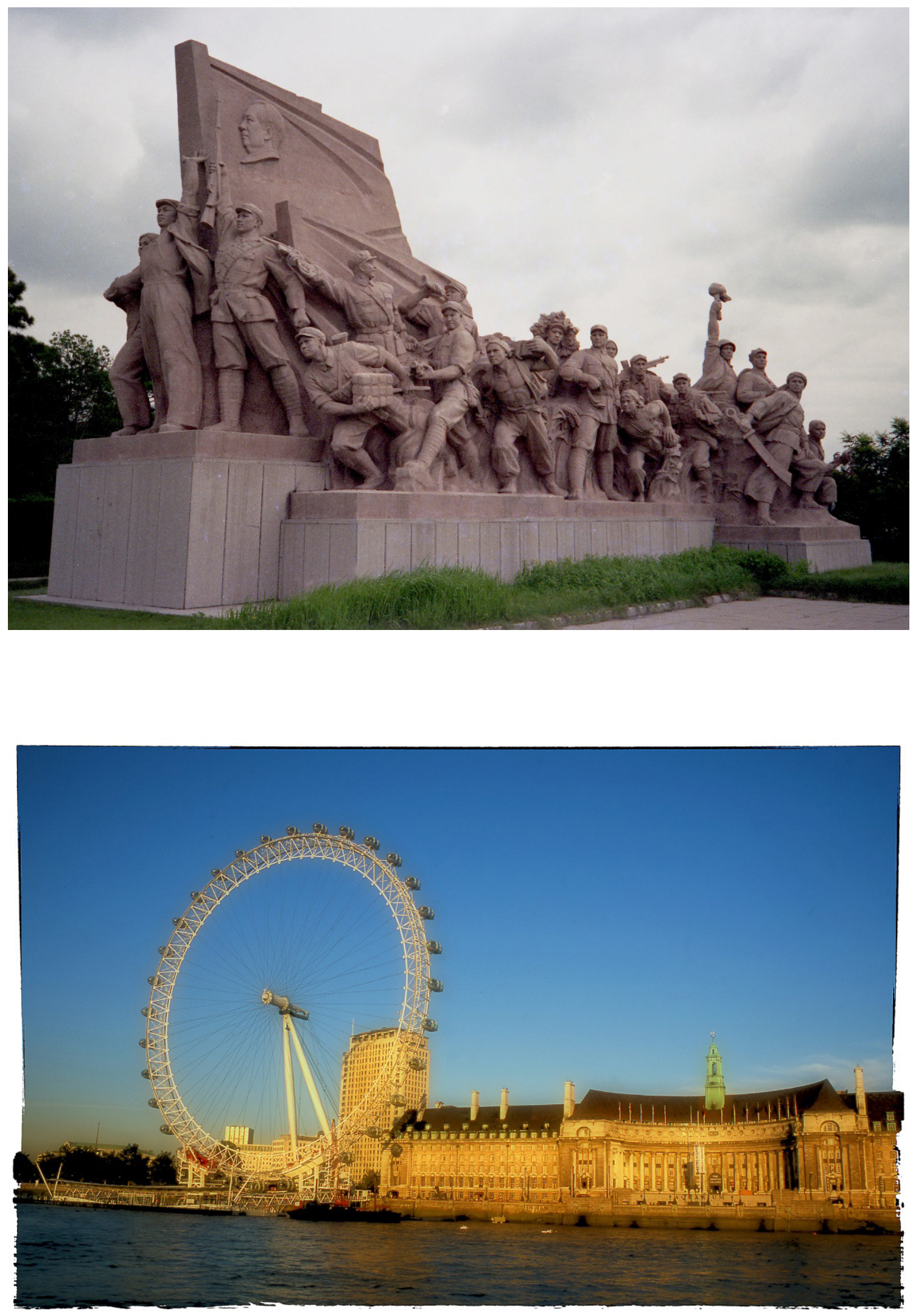